\title{
Caveolin-I enhances resveratrol-mediated cytotoxicity and transport in a hepatocellular carcinoma model
} \author{
Hui-ling Yang*1,3, Wei-qiong Chen ${ }^{1,3}$, Xuan Cao ${ }^{3}$, Andrea Worschech ${ }^{2,5,6}$, Li- \\ fen $\mathrm{Du}^{3}$, Wei-yi Fang4, Yang-yan $\mathrm{Xu}^{3}$, David F Stroncek ${ }^{7}$, Xin $\mathrm{Li}^{4}$, Ena Wang ${ }^{2}$ \\ and Francesco M Marincola*2
}

\begin{abstract}
Address: ${ }^{1}$ Institute of Clinical Medicine, First Affiliated Hospital of University of South China, Hengyang, 421001, PR China, ${ }^{2}$ Infectious Disease and Immunogenetics Section (IDIS), Department of Transfusion Medicine and Center for Human Immunology (CHI), National Institute of Health,10 Center Drive, Building 10, Bethesda, MD 20892, USA, ${ }^{3}$ Institutes of Pharmacology and Pharmacy, University of South China, Hengyang, 421001, PR China, ${ }^{4}$ Cancer Research Institute of Southern Medical University, Guangzhou 510515, PR China, ${ }^{5}$ Genelux Corporation, San Diego Science Center, San Diego, California, USA, 'Institute for Biochemistry, University of Würzburg, Am Hubland, Würzburg, Germany and ${ }^{7}$ Cellular Processing Section, Department of Transfusion Medicine, National Institutes of Health, Bethesda, Maryland, USA

Email: Hui-ling Yang* - yanghuiling3018@sina.com; Wei-qiong Chen - sunnychen823@163.com; Xuan Cao - inter315@sina.com; Andrea Worschech - worschecha@mail.nih.gov; Li-fen Du - du-lifen@163.com; Wei-yi Fang - fangweiyi1975@yahoo.com.cn; YangyanXu - xuhengyuy999@yahoo.com.cn; David F Stroncek - DStroncek@cc.nih.gov; Xin Li - xinli268@gmail.com;

Ena Wang - EWang@cc.nih.gov; Francesco M Marincola* - FMarincola@cc.nih.gov

* Corresponding authors
\end{abstract}

Published: 25 March 2009

Journal of Translational Medicine 2009, 7:22 doi:10.1186/1479-5876-7-22
Received: 24 February 2009

Accepted: 25 March 2009

This article is available from: http://www.translational-medicine.com/content/7/I/22

(c) 2009 Yang et al; licensee BioMed Central Ltd.

This is an Open Access article distributed under the terms of the Creative Commons Attribution License (http://creativecommons.org/licenses/by/2.0), which permits unrestricted use, distribution, and reproduction in any medium, provided the original work is properly cited.

\begin{abstract}
Background: Resveratrol (RES), an estrogen analog, is considered as a potential cancer chemopreventive agent. However, it remains unclear how RES is transported into cells. In this study, we observed that Caveolin-I(CAVI) expression can increase the cytotoxic and pro-apoptotic activity of RES in a dose- and time-dependent manner both in vitro and in vivo in a Hepatocellular Carcinoma animal model.
\end{abstract}

Methods: High performance liquid chromatography (HPLC) demonstrated that RES intra-cellular concentration is increased about 2-fold in cells stably expressing CAVI or CAVMI (a scaffolding domain (8I-IOIAA)-defective CAVI mutant) compared to the untransduced human Hepatoblastoma cell line (HepG2) or after transduction with the green fluorescent protein (GFP) control vector. The increased intra-cellular transport of RES was abolished in cells stably expressing CAVM2 (a cholesterol shuttle domain (I43-I56AA)-defective CAVI mutant) or CAVRNAi. In order to further characterize CAVI-dependent RES transport, we synthesized RESdansyl chloride derivatives as fluorescent probes to visualize the transport process, which demonstrated a distribution consistent with that of CAVI in HepG2 cells.

Results: In addition, RES endocytosis was not mediated by estrogen receptor (ER) $\alpha$ and $\beta$, as suggested by lack of competitive inhibition by estrogen or Tamoxifen. Pathway analysis showed that RES can up-regulate the expression of endogenous CAVI; this activates further the MAPK pathway and caspase- 3 expression.

Discussion: This study provides novel insights about the role played by CAVI in modulating cellular sensitivity to RES through enhancement of its internalization and trafficking. 


\section{Background}

Resveratrol (trans-3,4',5-trihydroxystilbene, RES), a phytoalexin found in grapes and other food products, is considered as a cardio-protective drug and a potential cancer chemo-preventive agent [1-6]. Through inhibitory effects on the oxidative modification of low density lipoproteins, RES can block internalization of oxidized lipoproteins responsible for its cardio-protective quality. In addition, RES can inhibit the growth of a variety of tumor cells in vitro and in animal models [7-9] through its anti-cancer properties including prevention, delay, and reversal of tumor initiation, promotion and progression. This is partly attributable to RES antioxidant activity and inhibitory effect on the hydroperoxidase activity of cyclooxygenase (Cox 1 and 2); furthermore, RES can inhibit transcription factors such as NF-kB, apoptotic protease activating factors (Apaf-1), and AHR, growth of estrogen responsive cells and induce accumulation of p53 [10-14]. Some studies indicated that RES has a molecular structure similar to diethylstilbesterol displaying estrogen-like agonistic and antagonistic activity. Therefore, RES could bind to the estrogen receptor (ER) and thereby activate the transcription of estrogen-responsive reporter genes [15-17]. However, most of the in vivo studies have failed to confirm the estrogen-like potential of RES.

Caveolins are plasma membrane rafts present in most cells, and were first characterized morphologically as small flask-shaped plasma membrane invaginations [18]. The typical caveolin-1 (CAV1) protein is a principal component of the caveolin family and its reduced or absent expression was shown in most human cancer cells. Several lines of evidence support CAV1 function as a "transformation suppressor" protein. Over expression of CAV1 blocks anchorage-independent growth of transformed cells. A varied array of functions has been proposed for caveolins, including modulation of signal transduction, endocytosis, potocytosis, and cholesterol trafficking. CAV1 can suppress epidermal growth factor tyrosine kinase (EGF), extra-cellular signal-regulated kinase (ERK), endothelial nitric-oxide synthase, threonine protein kinase, serine protein kinase such as Src family TK, PKC $\alpha$, H-Ras via the CAV1 scaffolding domain that combines with these genes [19-24]. In addition, some reports suggest that CAV1 mediates mitogen-activated protein kinase (MAPK)dependent CREB phosphorylation activating ER $\alpha$ and ER $\beta$ through its scaffolding domain similarly to ER $\alpha$ and ER $\beta$ activation by RES $[15-17,25]$. However, the CAV1dependent mechanism(s) by which RES may trigger cell signaling remains to be determined.

This study analyzes whether and how CAV1 is involved in the cytotoxic and pro-apoptotic actions of RES in a human hepatocellular carcinoma (HCC) model. Lentiviral vectors expressing short hairpin RNAs (shRNAs) against the CAV1 gene [26] such as wild type (Wt CAV1), a scaffold- ing domain (81-101AA)-defective CAV1 mutant (CAVM1) and a cholesterol shuttle domain (143-156AA)defective CAV1 mutant (CAVM2) were constructed and transfected into the human Hepatoblastoma cells HepG2; these cells display constitutively low levels of endogenous CAV1 $[27,28]$. The effects of WtCAV1, CAVM1 and CAVM2 expression on cell growth, apoptosis, and Topoisomerase- $\alpha$-Topo II/P38 transcription in response to various doses $(0 \sim 300 \mu \mathrm{m})$ of RES were analyzed in vivo and in vitro. Furthermore, the contribution of CAV1 to the influx and efflux of cellular RES was investigated by high performance liquid chromatography (HPLC) and its intracellular distribution by RES derivatives (RES-dansyl chloride) as fluorescent probes.

\section{Materials and methods Materials}

Plasmid extraction kit (Promega, Madison, USA), and BCA protein quantitative kit (Pierce, Rockford, USA) were purchased. BlueRanger pre-dye protein molecule standard and protein fluorescence detection kit were from HyClone (South Logan, USA). Rabbit anti-human CAV-1(N-20), extra-cellular signal-related kinase1/2 (ERK1/2, K-23) and p38 kinase(H-147) polyclonal antibodies; mouse antihuman caspase-3(E-8), mouse anti-Topoisomerase-alpa (Ki-S1), mouse anti-human $\beta$-actin monoclonal antibody and phosphorylated proteins of ERK1/2(p- ERK1/2(E-4)); Cy3-conjugated goat anti-mouse IgG, goat anti-rabbit immunoglobulin G (IgG) and goat anti-mouse IgG antibodies coupled to horseradish peroxidase were all from Santa Cruz Biotechnology (Santa Cruz, USA). Alexa Fluor 488 -conjugated goat anti-rabbit IgG $(\mathrm{H}+\mathrm{L})$ antibody, Lipofectamine 2000 reagent, geneticin (G418) and blasticidin were purchased from Invitrogen (Carlsbad, USA); Cell medium and antibiotics were from Gibco-BRL (Paisley, Scotland, United Kingdom). Fetal bovine serum (FBS) was from HyClone (Logan, UT). Dansyl Chloride was purchased from Amresco. Resveratrol(trans-3,4',5-trihydroxystilbene, RES), special P38 mitogen-activated protein kinases inhibitor (SB203580), trans-Ferulic acid(trans-4-Hydroxy-3-methoxycinnamic acid, t-FA), Diethylstilbestrol(DES), Tamoxifen citrate and all other reagents used for immunofluorescence and Western blots were from Sigma and of the highest grade available.

\section{Plasmids}

The mammalian GFP Fusion expression vector for human wild-type CAV1 was constructed by inserting the human CAV1 cDNA into pcDNA3.1/NT-GFP-TOPO [27]. Mutant CAV1 with the deletion of the scaffolding domain (CAVM1, CAV1-81-101aa) and mutant CAVM2 (lacking the lipid domain 143-156aa, CAVM2, CAV1-143-156) were generated by PCR mutagenesis using pcDNA3.1/NTGFP-TOPO-CAV1 as a template and the GFP reporter vector as previously described. We used lentiviral expressed short hairpin RNAs (shRNAs) against CAV1. 


\section{Cell culture}

The human Hepatoblastoma carcinoma-2 HepG2 cell line was obtained from the Cell Bank, Chinese Academy of Sciences Shanghai Institute of Cell Biology, and cultured in Dulbecco's modified Eagle's medium supplemented with $10 \%$ fetal bovine serum (HyClone), $100 \mu \mathrm{g} / \mathrm{ml}$ penicillin and streptomycin, $4 \mathrm{mM} / L$ glutamine, $1 \mathrm{mM}$ MEM sodium pyruvate in a humidified $37^{\circ} \mathrm{C}$ incubator with $5 \%$ $\mathrm{CO}_{2}$. One day prior to the transfection, cells were plated into a $10 \mathrm{~cm}$ tissue culture plate and grown to $90 \%-95 \%$ confluence. The day after, $9 \mu \mathrm{g}$ of plasmids (CAV1, CAVM1, CAVM2 and GFP reporter vector respectively) were transfected into the HepG2 cells using $10 \mu$ l of Lipofectamine 2000 reagent, according to the manufacturer's instructions. Forty-eight hours after transfection, Geneticin $(500 \mu \mathrm{g} / \mathrm{ml})$ was used to select stable transfectants. In addition, to obtain stable knockdown effect, the lentiviral supernatant expressed short hairpin RNAs (shRNAs) against the CAV1 gene was added into HepG2 cells, and $5 \mu \mathrm{g} / \mathrm{ml}$ blasticidin was used to select stable transfectants $48 \mathrm{~h}$ post-transduction. The medium was changed every 3 to 4 days until Geneticin or blasticidin-resistant colonies appeared. Single colonies were picked and grown in selection medium in 24-well-plates.

\section{Cell viability assay}

Cell viability was measured by MTT (3-(4,5-dimethylthiazol-2-yl)-2,5-diphenyl tetrazolium bromide) assay by solubilization the formazan with DMSO (dimethyl sulfoxide). Stable transfections of HepG2-CAV1, HepG2-CAV M1, HepG2-CAV M2, HepG2-GFP, HepG2-shRNACAV1 and vehicle control were seeded in 96-well plates at a density of 4000 cells/well. After overnight culture, the cell were treated with different final concentrations of RES $(0,10,20$, $30,50,100,150,200,300 \mu \mathrm{mol} / \mathrm{l})$. Control cultures containing absolute DMSO (0.1-0.3\% dimethyl sulfoxide) were also established. Different RES concentrations were prepared freshly at each use by dissolving RES powder in absolute DMSO followed by serial dilutions in medium. Experiments were done in triplicates. Cell viability was measured by MTT assay at 24,48 and $72 \mathrm{~h}$ culture time. The quantity of formazan product was measured by spectrophotometric microtiter plate reader (Dynatech Laboratories, Alexandria, VA) at $570 \mathrm{~nm}$ wavelength. Results were expressed as a percentage of growth, with $100 \%$ representing control cells treated with DMSO alone.

\section{Apoptosis and cell cycle distribution analysis}

Cells were plated in $10-\mathrm{cm}$ culture dishes and grown to $60-70 \%$ confluence within $24 \mathrm{hr}$. After overnight culture and cell adherence to the bottom, the culture medium was replaced by FBS-free DMEM. After 12 h, DMSO (0.1$0.3 \%)$ or RES $(0-300 \mu \mathrm{mol} / \mathrm{l})$ was added. Both adherent and floating cells were harvested $24 \mathrm{~h}, 48 \mathrm{~h}$ and $72 \mathrm{~h}$ after treatment. Subsequently, cells were fixed with $70 \%$ etha- nol in ice-cold PBS and stained with propidium iodide (final concentration of $50 \mathrm{mg} / \mathrm{L}$ ) in the dark for $30 \mathrm{~min}$ at room temperature. Finally, cells were subjected to apoptosis and cell cycle analysis by flow cytometry using a FACS Calibur. All experiments were performed in duplicate.

\section{RES treatment of the HepG2 xenografts in nude mice}

The mice in this study were supplied by the Vital River Laboratory Animal Technology Co. Ltd. (SCXK (Beijing), 2007-0001), which is certified by the Charles River Laboratories (CRL, USA). All mice were cared for and maintained in accordance with animal welfare regulations under an approved protocol by the Beijing Bureau of Science Animal. $40 \mathrm{Balb} / \mathrm{c}-\mathrm{nu}$ female nude mice weighing $17-20 \mathrm{~g}$ were randomly assigned to 5 groups. Xenografts were established by injecting $5 \times 10^{6}$ HepG2 cells with different stable transfectants (none, He-CAV1, He-CAVM1, He-CAVM2, He-GFP and He-CAVRNAi) in $200 \mu \mathrm{l} \mathrm{PBS}$ into the back of each mouse. Ten days after inoculation, mice were divided into a control group and a RES treatment group (each group including four mice; two CAVRNAi-transfected mice and one HepG2-transfected mouse died before RES administration). RES (15 mg/kg body) was administered intra-peritoneal once every other day for 21 consecutive days. Untreated HepG2-implanted mice were given sterilized water following the same schedule. Tumor volume was determined every 2-3 days by direct measurement with calipers and calculated using the formula, [width ${ }^{2}\left(\mathrm{~mm}^{2}\right) \times$ length $\left.(\mathrm{mm})\right] / 2$. After scarification on day 30 tumor specimens and livers of each animal were removed, weighed and the RES content in both tissues was determined using HPLC analysis.

\section{Resveratrol analysis by HPLC}

Cells were harvested in ice-cold PBS $\left(1 \mathrm{~mL}\right.$ per $50 \mathrm{~cm}^{2}$ flask) and pelleted at $1500 \times \mathrm{g}$ for 5 minutes after washing them twice in ice-cold PBS. Cells were re-suspended in 50 $\mu \mathrm{l}$ N-40 Cell Lysis Buffer (50 Mm Tris-HCl, $150 \mathrm{mM}$ $\mathrm{NaCl}, 1 \%$ Nonide P-40, pH7.8) and homogenized by sonication for 10 seconds on ice. The protein concentration of cell lysates was determined by a bicinchoninic acid (BCA) kit analysis. An equal volume of $5.6 \mu \mathrm{g} / \mathrm{ml}$ inner standard solution was added (trans-Ferulic acid dissolved in methanol). The mixture was vortexed for $5 \mathrm{~min}$, followed by centrifugation at $12,000 \times g\left(4^{\circ} \mathrm{C}\right.$ for $\left.15 \mathrm{~min}\right)$. Twenty $\mu$ samples were injected into the HPLC device (Agilent 1100 series), separated on columns (Hypersil C18), eluted by mobile phase consisting of methanol: water: phosphate acid = 45:55:0.1 (v:v), at a flow rate of $0.8 \mathrm{~mL} / \mathrm{min}$, room temperature, and detected by Diode Array Detector at $320 \mathrm{~nm}$. To test whether the molecular structure of RES is similar to diethylstilbestrol (DES), 10${ }^{6} \sim 10^{-4} \mathrm{M} / \mathrm{L}$ DES plus RES were set to compete for ER activation. Furthermore, $10^{-5} \mathrm{M} / \mathrm{L}$ Tamoxifen was added $4 \mathrm{~h}$ before RES administration. 


\section{Synthesis of RES derivative fluorescent probes}

RES derivatives were synthesized with the modification of dimethylaminonaphthalene sulfonyl chloride (dansyl chloride, DAN). After laser excitation of RES-DAN at $403.8 \mathrm{~nm}$ the emitted fluorescence of the RES derivates could be was measured at $530 \mathrm{~nm}$ and was assessed to compare the intra-cellular distribution of RES with that of CAV1. A solution of $228 \mathrm{mg}(1.0 \mathrm{mmol})$ of RES in $10 \mathrm{~mL}$ of acetone was added into a mixture of $1 \mathrm{~g}$ of $\mathrm{K}_{2} \mathrm{CO}_{3}$ and $10 \mathrm{ml}$ acetone in $\mathrm{N}_{2}$ atmosphere, $270 \mathrm{mg}(1.0 \mathrm{mmol})$ of DAN in $10 \mathrm{~mL}$ of acetone added in sequential drops while cooling with an ice/water bath. The reaction mixture was stirred for $20 \mathrm{~min}$ at room temperature and heated to reflux for $2 \mathrm{~h}$. The organic solution was filtered, dried by evaporation and allowed to crystallize in acetone to result in a yellow powder. Cells were then exposed to RES-DAN (300 $\mu \mathrm{mol} / \mathrm{L})$ for $2 \mathrm{~h}$, after washing them twice with icecold PBS. The intra-cellular distribution of recombinant CAV1 was detected by incubation with mouse anti-GFP monoclonal antibody (1:200) and Cy3-conjugated goat anti-mouse antibody (1:500) for $45 \mathrm{~min}$. After three additional washings, the co-localization of RES and CAV1 were observed and photographed using a Zeiss 510 laser confocal microscope [29].

\section{Confocal immunofluorescence imaging and immunohistochemistry}

After incubation with or without $200 \mu \mathrm{mol} / \mathrm{l}$ RES for $24 \mathrm{~h}$, cells were fixed with methanol/glacial acetic acid solution (3:1) for $15 \mathrm{~min}$, permeabilized with $0.25 \%$ Triton $+5 \%$ DMSO at $37^{\circ} \mathrm{C}$ for $20 \mathrm{~min}$, blocked with TBST containing $5 \%$ defatted milk powder at $37^{\circ} \mathrm{C}$ for $2 \mathrm{~h}$, incubated with rabbit anti-human CAV1 antibody and mouse anti-Topoisomerase-alpha (Ki-S1) $(1: 150)$ and blocked at $4^{\circ} \mathrm{C}$ overnight. Cells were then washed three times with TBST before and after incubation together with Alexa Fluor 488conjugated goat anti-rabbit IgG $(\mathrm{H}+\mathrm{L})$ antibody and Cy3conjugated goat anti-mouse antibody (1:500) for $45 \mathrm{~min}$. The results were observed and photographed using a Zeiss 510 laser confocal microscope. The paraffin-embedded tumor samples were cut in-5 $\mu$ m-thick sections with a microtome. After de-paraffinization, rehydration and antigen recovery, tissue sections were examined for expression of CAV1 and Topoisomerase-alpha proteins by CAV1 and Topoisomerase-alpha antibody. Primary antibody staining was followed by incubation with antimouse or anti-rabbit secondary IgG polymer conjugated with HRP or Alkaline phosphatase and signals were verified using Double Polymer Staining Detection System (ZSGB-BIO, China).

\section{Immunoblotting}

Immunoblotting of phosphorylated ERK1/2, p38 kinase, and caspase-3 was carried out using phospho-specific MAP kinase antibodies against phosphorylated sites of
ERK1/2, p38 kinase, or active caspase-3, respectively. As control, total ERK1/2, p38 kinase, and caspase-3 were analyzed with the respective specific antibodies following manufacturer's instructions (Santa Cruz Biotechnology). In brief, HepG2 cells or HepG2 Cells with different transfectants were starved for $24 \mathrm{~h}$ in $0.1 \%$ FBS DMEM at $37^{\circ} \mathrm{C}$, in a 5\% CO2 atmosphere incubator. Cells were then treated with RES $(10-200 \mu \mathrm{mol} / \mathrm{l})$ or DMSO $(0.1 \%)$ for $24 \mathrm{~h}$. In addition, another group of HepG2 cells treated with $20 \mu \mathrm{m}$ SB202190 for $1 \mathrm{~h}$ followed by treatment with $200 \mu \mathrm{M}$ RES were cultured for an additional $24 \mathrm{~h}$. Cells were then washed once with ice-cold PBS and lysed in 200 $\mu l$ lysis buffer (50 Mm Tris- $\mathrm{HCl}, 150 \mathrm{mM} \mathrm{NaCl}, 1 \%$ Nonide P-40, Ph 7.8) and protease inhibitor. After sonication and centrifugation $(10,000 \mathrm{~g}$ for $15 \mathrm{~min}$, ) equal lysates $(20 \mu \mathrm{g})$ were tested for levels of CAV1, phosphorylated ERKs, p38 kinase and caspase-3 levels by Western immunoblotting using specific antibodies and chemi-luminescence detection as previously described [30].

\section{Statistical analysis}

All experiments were repeated three times. Data are presented as the mean \pm SD. Statistical significance was evaluated by an ANOVA and a Bonferroni adjustment applied to the results of a $t$-test performed with SPSS software. Differences between groups were analyzed by a Student's $t$ test. $P<0.05$ was considered statistically significant.

\section{Results \\ Dose-and time-dependent cell death induced by RES in human hepatoblastoma carcinoma HepG2 cells}

To determine whether CAV1 is involved in the cytotoxic and pro-apoptotic activity of RES, HepG2 cells were treated with different doses of RES $(0,10,30,50,100,200$ and $300 \mu \mathrm{mol} / \mathrm{L})$. MTT and flow cytometry were used to detect inhibitory effects of RES on the growth of serumstimulated HepG2 cells. As shown in Table 1 and 2 and Figure $1 \mathrm{~A}$ and Figure $1 \mathrm{~B}$, the MTT assay indicates that RES inhibits significantly the growth of serum-stimulated HepG2 cells in a concentration-dependent manner. Cell cycle distribution indicated that high concentrations of RES induced a marked increase in cell number in sub-G1 and G0/G1 phase, with a corresponding decrease in other phases. Interestingly, concentrations of RES between 10 and $100 \mu \mathrm{M}$ induced a modest but reproducible increase in cells at $S$ phase. Increased apoptosis ratios were observed at increasing RES concentrations (Tables 3 and 4 and Figure 1). HepG2 cells were also treated with 200 $\mu \mathrm{mol} / \mathrm{L}$ RES for 24, 48 and $72 \mathrm{~h}$; cell growth inhibition increased in time in the control HepG2 cell lines from $55.45 \pm 1.4,68.91 \pm 1.8,78.83 \pm 3.9$ compared to baseline levels after 24, 48 and $72 \mathrm{~h}$ respectively. Significant increase of growth inhibition ratio was observed in HepG2 cells over-expressing CAV1 (68.32 \pm 2.0, 80.12 \pm $1.7,90.02 \pm 4.0$, Table 2 ) and a significant reduction was 
Table I: Cell growth inhibition of HepG2 cells by $24 \mathrm{~h}$ treatment with $0.1-0.3 \%$ DMSO, RES or 5-FU

\begin{tabular}{|c|c|c|c|c|c|c|c|c|c|}
\hline \multicolumn{10}{|c|}{ Cell growth inhibition ratio (\%) } \\
\hline \multirow[t]{2}{*}{ Cell groups } & & & \multicolumn{5}{|c|}{$\operatorname{Res}(\mu \mathrm{M})$} & \multicolumn{2}{|c|}{ 5-FU $(\mu \mathrm{M})$} \\
\hline & DMSO & 10 & 20 & 30 & 50 & 100 & 200 & 300 & 100 \\
\hline HepG2 & 0.046 & 11.88 & 17.49 & 22.03 & 30.50 & 45.95 & 51.45 & 65.93 & 50.86 \\
\hline CAVI & 0.035 & 19.72 & $24.08 *$ & $37.13^{*}$ & $45.54^{*}$ & $57.54^{*}$ & $68.32^{*}$ & $87.89 *$ & $64.66^{*}$ \\
\hline CAVMI & 15.97 & 22.63 & 25.03 & 33.82 & 45.98 & 55.78 & 72.34 & 48.48 & 0.047 \\
\hline CAVM2 & 13.91 & 19.39 & 26.44 & 34.77 & 47.55 & 57.27 & 76.56 & 42.46 & 0.029 \\
\hline RNAi & 0.023 & 8.15 & 12.94 & $16.07 *$ & $24.34 *$ & $33.52 *$ & $41.23 *$ & $55.37 *$ & $32.83 *$ \\
\hline GFP & 0.034 & 10.32 & 18.07 & 22.34 & 30.84 & 45.37 & 54.04 & 67.12 & 53.23 \\
\hline CAVI & 0.035 & 19.72 & $24.08^{*}$ & $37.13^{*}$ & $45.54^{*}$ & $57.54^{*}$ & $68.32^{*}$ & $87.89 *$ & $64.66 *$ \\
\hline
\end{tabular}

$* \mathrm{P}<0.05$ vs control, $[\bar{x} \pm \mathrm{SD}, \mathrm{SD}=0.8 \sim 2.5), \mathrm{n}=3]$

RNAi = CAVRNAi

observed in HepG2 cells in which CAV1 activity was inhibited (CAVRNAi). CAV1 and CAVM2 over-expressing HepG2 cells induced spontaneous apoptosis and increased the cytotoxic and pro-apoptotic effects of RES. CAV1 or CAVM2 promote apoptotic cell death by inducing plasma membrane crimple, small volume changes, increased density and changes in nuclear morphology (Figure 1C). A statistically significant difference ( $\mathrm{p}<0.05$ ) was observed in apoptotic index at 50,100, 200 and 300 $\mu \mathrm{mol} / \mathrm{L}$ RES concentrations $(10.93 \pm 1.5,31.2 \pm 2.1,63.2$ $\pm 0.8,80.6 \pm 1.9)$ in CAV1 over-expressing cells $(17.91 \pm$ $2.5,78.7 \pm 1.7,93.6 \pm 2.0,97.1 \pm 1.7$, Table 3 ). In contrast, apoptotic cells were significantly reduced in HepG2 cells expressing scaffolding domain deleted (CAV1 $\left.{ }^{\Delta} 81-101\right)$ mutant. Down-regulation of CAV1 expression by shRNA correlated with decreased RES-induced growth inhibition (Table 3). These results suggest that RES can induce a dose- and time-dependent death of HepG2 cells, and over-expression of CAV1 can increase the cytotoxic and pro-apoptotic activity of RES even more.

\section{Synergistic anti-tumor activity of RES and CAVI in nude mice}

The above results indicate that CAV1 is a potentiator of the effects of RES on HepG2 cells in vitro. We next evalu-

Table 2: Cell growth inhibition of HepG2 cells by 24,48 and $72 \mathrm{~h}$ treatment with $200 \mu$ M RES

\begin{tabular}{lccc}
\hline Cell groups & \multicolumn{3}{c}{ Cell growth inhibition ratios (\%) } \\
& $24 \mathrm{~h}$ & $48 \mathrm{~h}$ & $72 \mathrm{~h}$ \\
\hline time & & & \\
& & & \\
DMSO & $55.45 \pm 1.4$ & $68.91 \pm 1.8$ & $78.83 \pm 3.9$ \\
CAVI & $1.00 \pm 0.9$ & $1.53 \pm 1.6$ & $1.72 \pm 0.7$ \\
CAVMI & $68.32 \pm 2.0^{*}$ & $80.12 \pm 1.7^{*}$ & $90.02 \pm 4.0^{*}$ \\
CAVM2 & $55.78 \pm 1.0$ & $74.83 \pm 2.8$ & $82.46 \pm 1.6$ \\
CAVRNAi & $57.27 \pm 1.2$ & $76.79 \pm 1.6$ & $84.35 \pm 2.6$ \\
GFP & $41.23 \pm 1.5^{*}$ & $55.39 \pm 1.2^{*}$ & $68.27 \pm 1.9^{*}$ \\
& $54.04 \pm 1.6$ & $70.06 \pm 1.1$ & $76.27 \pm 1.7$ \\
\hline
\end{tabular}

$* \mathrm{P}<0.05$ vs control, $(\bar{x} \pm \mathrm{SD}, \mathrm{n}=3)$ ated the activity of CAV1 mutants on the growth of HepG2 cells in nude mice subjected or not to RES treatment. HepG2 cells expressing the different CAV1 mutants $\left(5 \times 10^{6}\right.$ cells/animal) were implanted subcutaneously in the animals back. Within 30 days of implantation, GFP control vector HepG2 cells had an average tumor size of $400 \pm 15 \mathrm{~mm}^{3}$. In contrast, xenografts from cells stably expressing CAV1 or CAVM2 were significantly smaller with an average tumor size of $325 \pm 10 \mathrm{~mm}^{3}$ and $340 \pm$ $13.4 \mathrm{~mm}^{3}$ (Figure 2 and Table 5). On the other hand the over-expression of mutant CAVM1 protein with deletion of the scaffolding domain 80-101aa promoted proliferation and malignant transformation compared to the parental cell lines and GFP vector-only transfectants (586 $\left.\pm 21 \mathrm{~mm}^{3}\right)$. RES ( $15 \mathrm{mg} / \mathrm{kg}$ body) administered intra-peritoneal every other day for 21 consecutive days starting at day 10 after tumor cell inoculation induced significant inhibition of tumor growth in all HepG2 cells whether wild type or expressing one of the various mutant constructs (Table 5). However, regression was more dominant in xenografts of HepG2 cells stably expressing CAV1. Furthermore, RES could reverse CAVM1 or CAVRNAi proliferative effects.

\section{HPLC analysis of RES-treated cells}

After incubation with RES (50, 100, 150, 200, 250, 300 $\mu \mathrm{M})$ for $2 \mathrm{~h}, 10 \mathrm{~h}, 24 \mathrm{~h}$ and $48 \mathrm{~h}$, HepG2 cell plasma extracts were analyzed by HPLC. Intra-cellular RES concentration was increased in a dose- and time-dependent manner, but lower than the RES concentration in the supernatant (Data not shown). We therefore addressed whether CAV1 can induce endocytosis specifically and indeed intra-cellular RES concentration was increased about 2-fold in HepG2 cells stably expressing CAV1 or CAVM1 compared to HepG2 wild-type or GFP-transduced. Conversely, increased intra-cellular transport disappeared in cells stably expressing CAVM2 and CAVRNAi (Figure 3). To test whether the potential similar molecular structure of RES compared with DES may also display estrogen-like agonistic and antagonistic activity, we mixed 
Table 3: Apoptosis induction in HepG2 cell variants by $48 \mathrm{~h}$ treatment with DMSO or 20-300 $\mu$ M RES

\begin{tabular}{|c|c|c|c|c|c|c|}
\hline \multirow{3}{*}{ Cell groups } & \multicolumn{6}{|c|}{ Percent Apoptosis (\%) } \\
\hline & \multirow{2}{*}{ DMSO } & \multicolumn{5}{|c|}{$\operatorname{Res}(\mu M)$} \\
\hline & & 20 & 50 & 100 & 200 & 300 \\
\hline HepG2 & $1.53 \pm 1.6$ & $6.83 \pm 1.9$ & $10.93 \pm 1.5$ & $31.2 \pm 2.1$ & $63.2 \pm 0.8$ & $80.6 \pm 1.9$ \\
\hline CAVI & $3.62 \pm 1.8$ & $13.2 \pm 1.0$ & $|7.9| \pm 2.5^{*}$ & $78.7 \pm 1.7^{*}$ & $93.6 \pm 2.0^{*}$ & $97.1 \pm 1.7^{*}$ \\
\hline CAVMI & $2.19 \pm 1.8$ & $9.62 \pm 1.1$ & $13.5 \pm 1.8$ & $23.1 \pm 0.9$ & $74.1 \pm 1.8^{*}$ & $90.3 \pm 0.6^{*}$ \\
\hline CAVM2 & $3.08 \pm 1.3$ & $11.5 \pm 1.4$ & $15.3 \pm 1.6$ & $50.1 \pm 1.7^{*}$ & $83.4 \pm 1.5^{*}$ & $93.5 \pm 2.4^{*}$ \\
\hline CAVRNAi & $1.37 \pm 1.7$ & $5.05 \pm 1.4$ & $9.78 \pm 1.1$ & $24.8 \pm 2.5$ & $57.7 \pm 2.4$ & $75.4 \pm 3.1$ \\
\hline GFP & $1.44 \pm 1.1$ & $6.05 \pm 1.8$ & $11.2 \pm 2.0$ & $32.7 \pm 1.6$ & $65.4 \pm 2.1$ & $82.3 \pm 3.0$ \\
\hline
\end{tabular}

$* \mathrm{P}<0.05$ vs control, $(\bar{x} \pm \mathrm{SD}, \mathrm{n}=3)$

$10^{-6} \sim 10^{-4} \mathrm{M} / \mathrm{L}$ DES plus RES in a competitive assay. Intracellular RES concentration was not significantly different between the two conditions. Thus, RES concentration was increased two-fold in CAV1, CAVM1 HepG2 cells compared to HepG2 wild-type or GFP-transfectants independent of DES treatment (Figure 3D, E and Figure 3F). Furthermore, the estrogen receptor (ER) was blocked by $10^{-5} \mathrm{M} / \mathrm{L}$ Tamoxifen citrate without altering the results (data not shown) suggesting that CAV1 induces endocytosis specifically and independent of ER activation. Furthermore, this data suggest that the 143-156 amino acids of the lipid-binding domain of CAV1 play a key role. On the contrary, the 81-101 amino acids scaffold-domain of CAV1 is irrelevant to CAV1-mediated internalization and trafficking of RES.

\section{Co-localization of RES and CAVI}

To gather additional supporting evidence that RES may be transported into cells by CAV1 via its cholesterol shuttle domain, the co-localization of RES and CAV1 was investigated in HepG2 cells. Dansyl chloride-derived RES stained with green fluorescence (Figure 4A section A) and recombinant CAV1 staining with red fluorescence (Figure 4A section B) co-localized in the CAV1-expressing HepG2 (Figure 4A section $\mathrm{C}$ ). We then analyzed the distribution of RES and CAVM2 (a cholesterol binding domain-defec- tive CAV1 mutant) in pooled HepG2 cells and the overexpressing CAVM2 cells which displayed similar distribution of RES (Figure 4A section D). However, the overexpressing CAVM2 cells could be distinguished from non transfected HepG2 cells because of the red fluorescence (Figure 4A section E). In these cells, the labeling occurred mainly close to the membrane of the HepG2 cell and to a lesser extent in the cytoplasm where only a weak co-localization with RES could be observed (Figure 4A section F). These data strongly suggest that RES is transported into cells by CAV1.

\section{Confocal immunofluorescence and immunohistochemistry} CAV1 and topoisomerase-alpha protein expression in tissue and cells was studied by Immunofluorescence and Immunohistochemistry. As shown in Figure $4 \mathrm{~B}$ and Figure 4C CAV1 and topoisomerase-alpha proteins were minimally expressed by HepG2 cells and respective xenografts not treated with RES. CAV1 was predominantly located around the cell membrane while topoisomerasealpha was found in the nuclei. RES pre-treatment (100 $\mu \mathrm{M}$ ) promoted the expression of CAV1 or topoisomerasealpha while topoisomerase-alpha expression was inhibited completely in CAVRNAi cells. However, $100 \mu \mathrm{M}$ RES pre-treatment recovered topoisomerase-alpha expression in CAVRNAi cells.

Table 4: Cell cycle distribution of HepG2 cells after treatment with or without RES for $\mathbf{4 8 ~ h}$

\begin{tabular}{|c|c|c|c|c|c|c|c|c|c|c|c|c|c|c|c|}
\hline \multirow{4}{*}{ Cell groups } & \multirow{2}{*}{\multicolumn{15}{|c|}{$\begin{array}{l}\text { Cell cycle distribution } \\
\text { Res }(\mu \mathrm{M})\end{array}$}} \\
\hline & \multicolumn{14}{|c|}{$\operatorname{Res}(\mu M)$} & \\
\hline & \multicolumn{3}{|c|}{ DMSO } & \multicolumn{3}{|c|}{20} & \multicolumn{3}{|c|}{50} & \multicolumn{3}{|c|}{100} & \multicolumn{3}{|c|}{200} \\
\hline & GI & G2 & $\mathrm{S}$ & GI & $\mathrm{G} 2$ & S & GI & G2 & S & GI & G2 & S & GI & G2 & $S$ \\
\hline HepG2 & 76.3 & 9.6 & 14.1 & 73.0 & 13.5 & 13.5 & 25.3 & 4.8 & $69.9 *$ & 34.9 & 7.4 & $57.7^{*}$ & $72.7^{*}$ & 8.8 & 18.5 \\
\hline CAVI & 57.9 & 10.0 & 32.1 & 15.4 & 7.5 & $77.1^{*}$ & 27.5 & 21.4 & $51.1 *$ & $65.8^{*}$ & 1.6 & 32.6 & $73.5^{*}$ & 24.2 & 2.3 \\
\hline CAVMI & 58.9 & 16.0 & 25.0 & 69.5 & 8.9 & 21.6 & 33.9 & 10.5 & $55.7^{*}$ & 39.9 & 20.0 & $40.1^{*}$ & $79 *$ & 8.6 & 12.4 \\
\hline CAVM2 & 68.2 & II.I & 20.7 & 72.5 & 3.8 & 23.7 & 30.5 & 8.4 & $61.1 *$ & $75.8^{*}$ & 3.1 & 21.1 & $74.1 *$ & 8.5 & 17.4 \\
\hline CAVRNAi & 57.8 & 10.2 & 38.1 & 45.3 & 16.4 & 32.3 & 37.5 & 21.1 & $55.0^{*}$ & $64.9 *$ & 19.5 & 15.7 & $69.2^{*}$ & 13.1 & 17.7 \\
\hline GFP & 77.4 & 5.9 & 16.7 & 73.2 & 14.0 & 12.5 & 22.3 & 6.0 & $71.7^{*}$ & 30.4 & 7.8 & $61.8^{*}$ & $70.0 *$ & 10.5 & 20.5 \\
\hline
\end{tabular}

$* \mathrm{P}<0.05$ vs control, $[\bar{x} \pm \mathrm{SD}, \mathrm{SD}=(0.8 \sim 3.7), \mathrm{n}=3]$ 
A

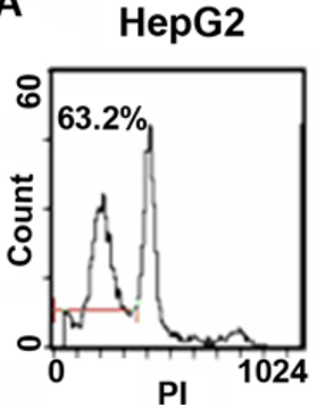

CAVM2

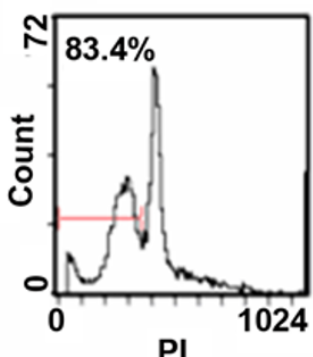

PI
CAV1

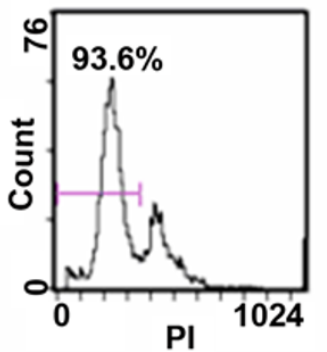

CAVRNAi

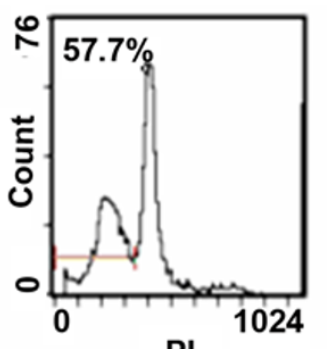

$\mathrm{PI}$
CAVM1

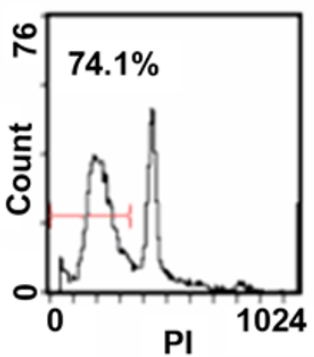

GFP

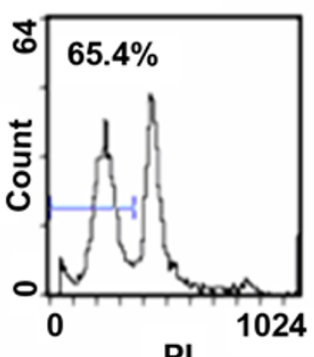

B

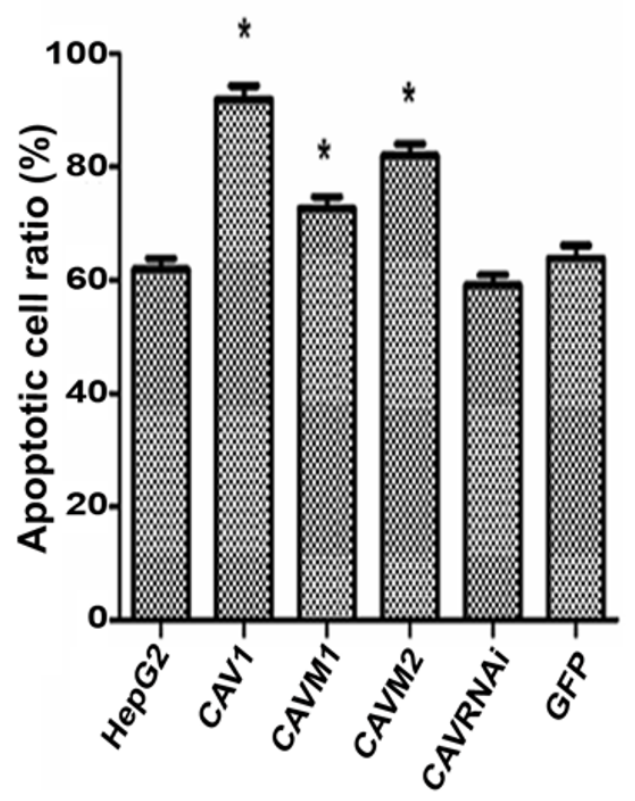

C

HepG2-CAV1-GFP

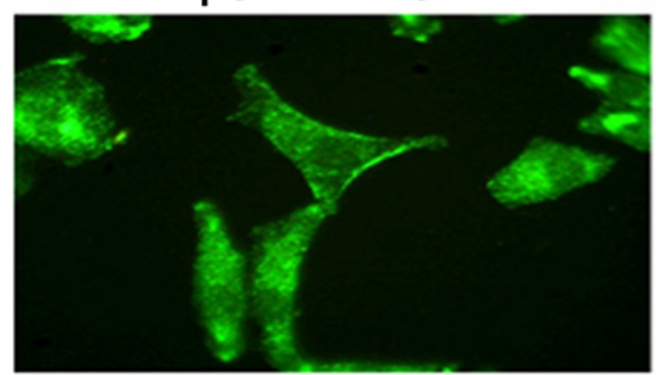

HepG2-CAVM2-GFP

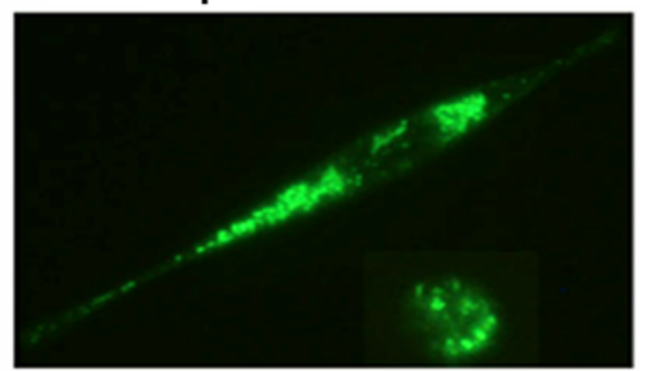

Spontaneous apoptosis in HepG2-CAV1-GFP or HepG2-CAVM2-GFP
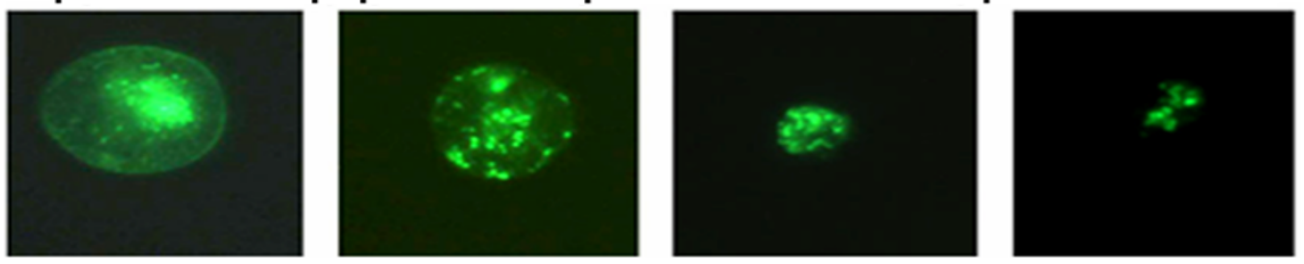

Figure I

(A) The six cell groups were pre-treated with $200 \mu \mathrm{M}$ RES for $48 \mathrm{~h}$, and apoptotic cell ratios were then measured by flow cytometry. (B) Percentage of dead cells calculated for HepG2 cells variants treated with $200 \mu M$ RES for $48 \mathrm{~h}$. Percentage of cell death was calculated over control. Data are presented as mean \pm SD. Values represent the average of three different experiments. (C) Fluorescence imaging of CAVI and CAVM2 overexpressing cells. *, statistical differences from the HepG2 cell control, $\mathrm{p}<0.05$.

RES increases CAVI expression and MAPKs activity in HepG2 cells

Previous studies showed that RES induces apoptosis through a caspase-dependent pathway. Therefore, the activity of caspase 3, a major component of the caspase pathways, was analyzed. In addition, the role ERKs and p38 kinase in regulation of caspase-3 -mediated apoptosis was studied by exposing cells to either DMSO (0.1-0.3\%) or RES (0-200 $\mu \mathrm{mol} / \mathrm{l})$ for $24 \mathrm{~h}$. CAV1, MAPKs, and caspase-3 protein levels were then determined by western blot. The data suggested that RES induces CAV1 expression in a dose-dependent manner from $30-50 \mu \mathrm{M}$ and reached a peak value with higher concentration. Twentyfour hours after RES treatment, pro-caspase activity was 
Table 5: Effect of RES on HepG2 variant xenograft weight

\begin{tabular}{|c|c|c|c|c|c|}
\hline Group & $\begin{array}{c}\text { RES } \\
\text { (mg/kg) }\end{array}$ & $\mathbf{n}$ & $\begin{array}{c}\text { Tumor } \\
\text { weight } / \mathrm{mg}\end{array}$ & Inhibitory rate \% & Intra-group inhibitory rate\% \\
\hline HepG2 & 0 & 4 & $222.50 \pm 22.5$ & & \\
\hline HepG2 & 15 & 4 & $173.33 \pm 33.3^{a}$ & 22.11 & 22.11 \\
\hline CAVI & 0 & 4 & $165.50 \pm 10.2 \mathrm{a}$ & 25.84 & \\
\hline CAVI & 15 & 4 & $92.50 \pm 15.1^{b}$ & 58.43 & 44.12 \\
\hline CAVMI & 0 & 4 & $337.50 \pm 20.6 \mathrm{a}$ & -51.68 & \\
\hline CAVMI & 15 & 4 & $117.50 \pm 12.5^{b}$ & 47.19 & 65.19 \\
\hline CAVM2 & 0 & 4 & $170.00 \pm 18.9 a$ & 23.61 & \\
\hline CAVM2 & 15 & 4 & $142.50 \pm 15.1^{b}$ & 35.96 & 16.17 \\
\hline CAVRNAi & 0 & 2 & $247.50 \pm 7.07$ a & $-|1.2|$ & \\
\hline CAVRNAi & 15 & 4 & $230.00 \pm 6.80^{b}$ & -3.37 & 7.07 \\
\hline
\end{tabular}

Values are means \pm SEM, $n=4$.

a. $P<0.05$ vs control group.

b. $P<0.05$ vs corresponding untreated group (RES at doses of $0 \mathrm{mg} / \mathrm{kg}$ )

reduced, and cleaved active caspase- 3 was increased (Figure 5A). Phosphorylation of MAP kinases is essential for full kinase activation. Using phospho-specific antibodies against p38, ERKs and active caspase-3, we found that RES induced a rapid and prolonged activation of ERKs (10-50 $\mu \mathrm{M}$ ) (4.1- fold induction compared to control), as well as activation of CAV1 or ERKs. Furthermore, RES increased, p-p38 and active caspase-3 expression (2.1-fold induction compared with control), whereas total ERKs and p38 kinase expression did not change. Similar results were detected in CAV1 expressing mutant cell lines (Figure 5B).

Inhibition of p38MAP kinase leads to decreased apoptosis As shown in Figure 1 and Table 1, RES treatment for $24 \mathrm{~h}$ induced apoptotic death in HepG2 cells. Activation of p38MAPK is involved in caspase-3-dependent cell death, but the role of p38 MAPK in RES-induced CAV1 expression and consequent apoptosis of HepG2 cells was not known. Therefore, HepG2 cells were pre-treated with the specific p38MAPK inhibitor SB203580 in presence or absence of RES and CAV1 and active caspase-3 expression were measured by Western blot. Indeed $20 \mu \mathrm{M}$ SB203580 significantly reduced levels of RES-induced phosphop38MAPK Resveratrol which was associated with significant differences in CAV1 protein expression and consequent apoptosis (Figure 5C).

\section{Discussion}

Hepatocellular carcinoma (HCC) is the fifth most common cancer and accounts for more than 1 million deaths annually. The incidence of HCC in the Southeast Asia continues to rise steadily. Several systemic chemotherapies have been tested unsuccessfully against HCC, which remains incurable. Estrogen receptors (ERs) are localized to many sites within the cell, exposure to estrogens is a major known risk factor for breast cancer and other estrogen-mediated cancers. Experimental models suggest that estrogens stimulate hepatocyte proliferation in vitro and promote HCC growth in vivo. RES is a bioflavonoid that exists as cis- and trans-isomers, and the trans-isomer has greater anticancer and cardio-protective properties than the cis-isomer. As an estrogen analog activating ER $\alpha$ and ER $\beta$, RES was suggested as a candidate chemo-preventive agent and a treatment option for HCC. CAV1, a member of Caveolin family may represent a tumor suppressor abolishing anchorage-independent growth of transformed cells and it is poorly expressed in HCC [31]. The close coupling between RES and CAV1 is suggested by $\mathrm{ER} \alpha$ and ER $\beta$ co-localization within caveolin/lipid rafts and direct associations with caveolin-1 via its special scaffolding domain (amino acids 80 to 101). Therefore, we questioned whether RES interacting with CAV1 could suppress the proliferation of HCC. Preliminary experiments excluded the possibility that the CAV1-mediated activity of RES was due to direct CAV1-dependent activation of $E R \alpha$ and $E R \beta$ and proposed a novel mechanism responsible for RES-CAV1 mediated anti-cancer activity in HCC.

In this report, the data in HepG2 cells indicate that RES could inhibit the proliferation of HepG2 cells and increase their apoptosis in a time and dose-dependent fashion. In addition, our results are consistent with the notion that CAV or CAVM2 promote apoptotic cell death by inducing plasma membrane crimple, small volume changes, increased density, DNA fragmentation and changes in nuclear morphology. However, increased proliferation was not accompanied by a reduction in cell death in CAVM1 cells. An intriguing mechanism, in this regard, is the presence of scaffolding domain in caveolin1 that binds to and inhibits the activity of several signaling proteins in vitro and in situ, including the EGF and Neu receptors, Src-family kinases (Src/Fyn), PKCs, eNOS and the heterotrimeric G-proteins [32]. Thus, it remains to be explained why over-expression of CAV1 by stable transfection enhances the anti-proliferative and pro-apoptotic effects of RES whereas knocking down CAV1 expression 
A

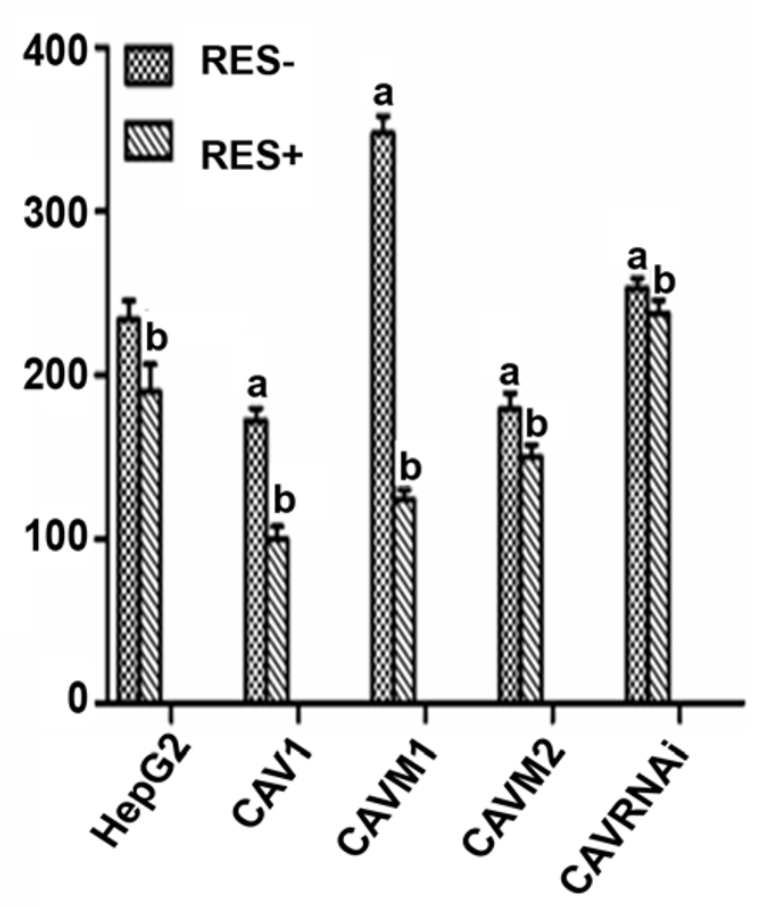

C

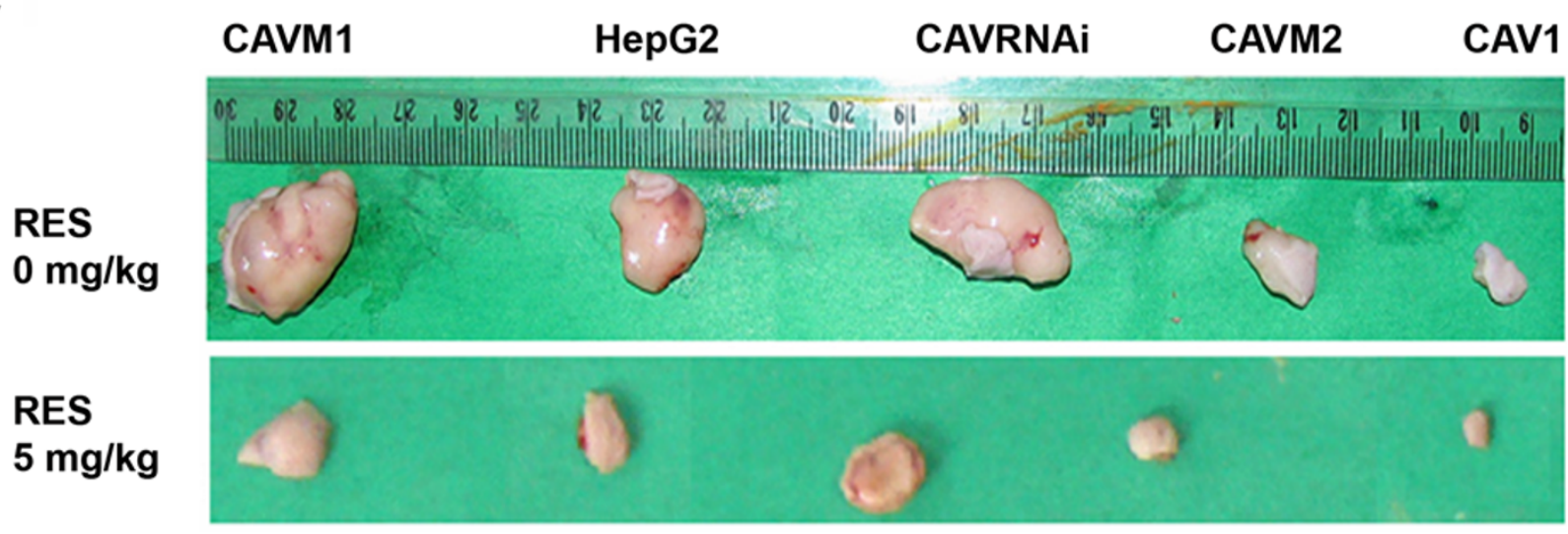

B

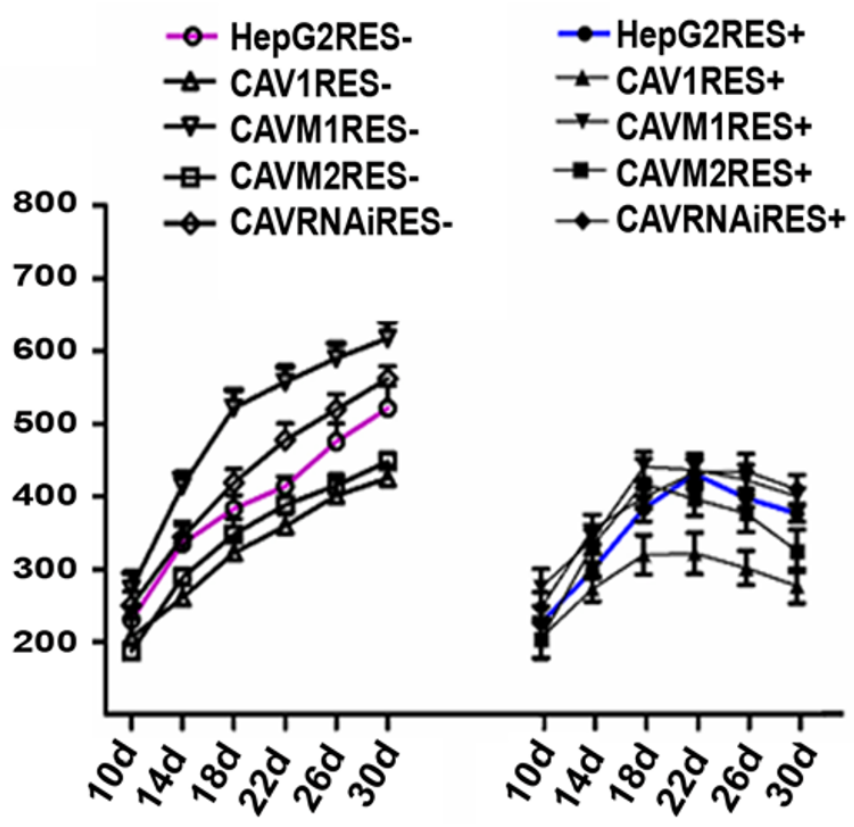

Figure 2

Effects of RES treatment on final tumor weight $(A)$ and volume $(B, C)$ in HepG2 cell variant xenografts. CAVI, CAVMI, CAVM2, CAVRNAi and HepG2 cells $\left(5 \times 10^{6}\right.$ cells $\left./ 0.2 \mathrm{ml}\right)$ were implanted subcutaneously into the back of Balb/c-nu female mice on day 0 . RES treatment ( $15 \mathrm{mg} / \mathrm{kg}$ body) was started ten days after implantation. The tumor volume was calculated every 2 to 3 day. Values represent means $\times S E M, n=4$. a. $P<0.05$ vs. control group. b. $P<0.05$ vs. corresponding untreated group.

by RNAi technology induces the inverse result. Whether this observation reflects merely the superimposition of two tumor suppressor mechanisms, or CAV1 can interact synergistically with RES remains to be clarified.

Most chemo-therapeutic agents can traffic effectively to tumors and deliver their cytotoxic functions; however drug resistance is rapidly acquired predominantly through altered entrance of the drug inside cancer cells. This failure is due to rapid elimination by membrane proteins of intracellular anticancer agents pumped out of cells and cell organelles, decreasing intracellular concentrations and efficacy [33]. The HPLC data suggest that the distribution of RES is imbalanced between intra-cellular and extra-cellular compartments. Despite increased intracellular concentrations in a dose- and time-dependent 
A

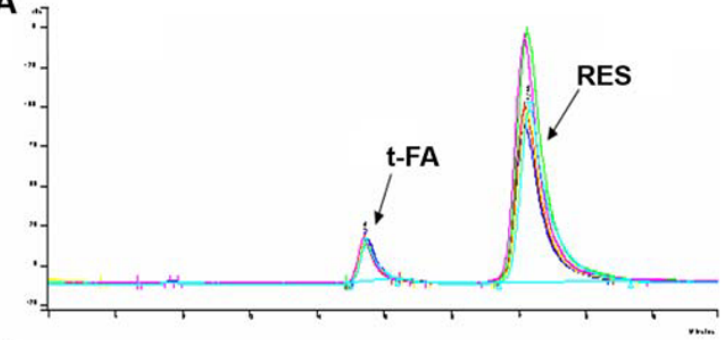

B

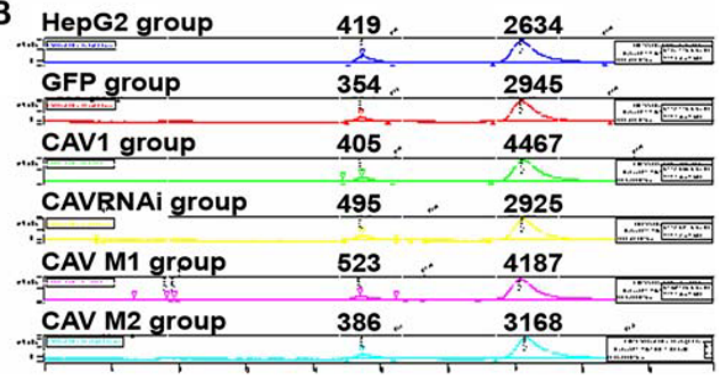

C

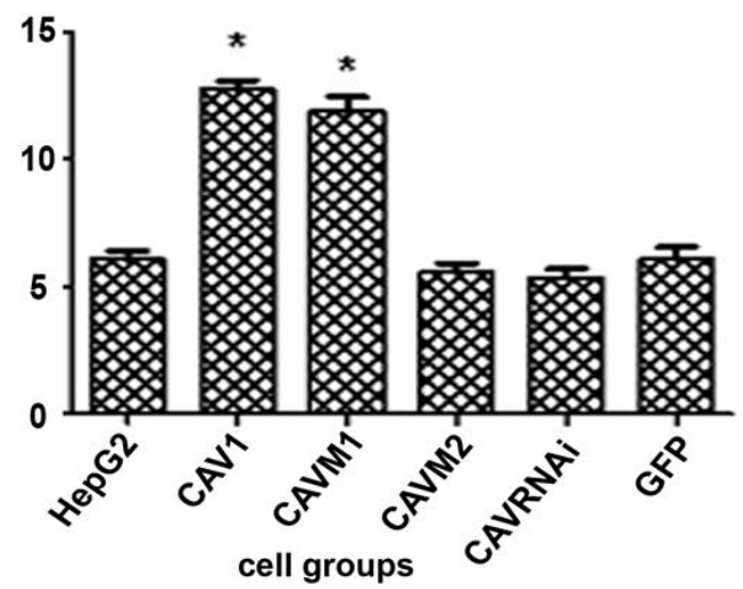

D
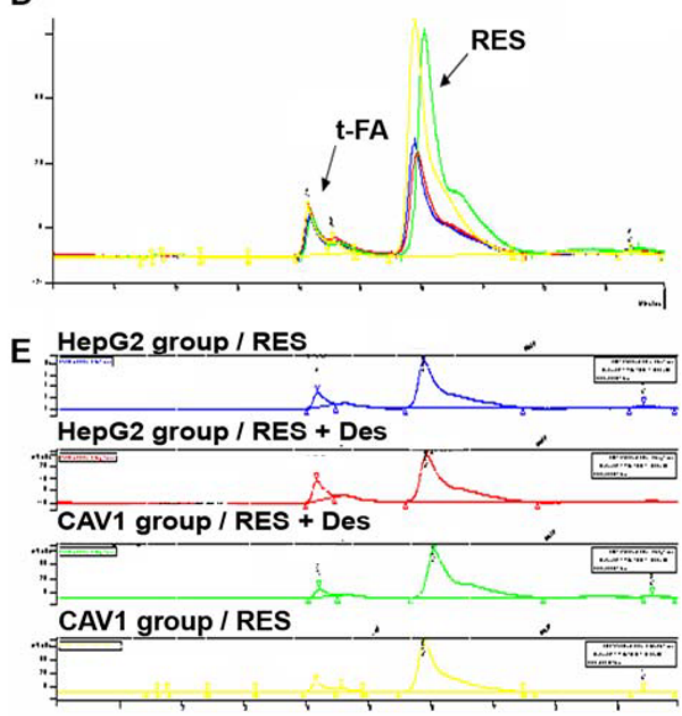

$\mathbf{F}$

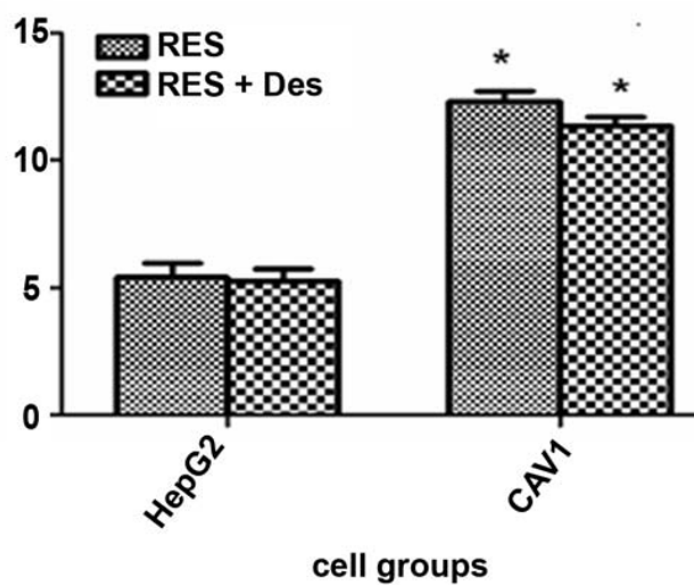

\section{Figure 3}

(A) HepG2 variants were pre-treated for $24 \mathrm{~h}$ with $200 \mu \mathrm{M}$ RES and RES concentrations were detected in the cytoplasm by HPLC. (B) - Values for individual variants. (C) - Res concentration in the cytoplasm of individual HepG2 cells after $24 \mathrm{~h}$ pre-treatment with $200 \mu \mathrm{M}$ RES. Each bar represents the mean \pm S.E.M. of three independent experiments. (D)

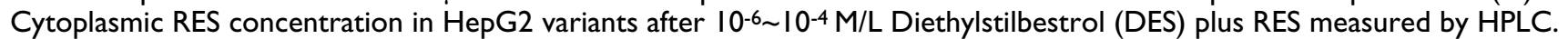
(E) Individual variant values. (F) Mean \pm S.E.M. values of three individual experiments. *, statistically significant differences between experimental variant and HepG2 cell control, $\mathrm{p}<0.05$.

manner, RES levels were always lower than in the supernatant (Data not shown). Interestingly, we found that intra-cellular RES concentration was increased 2-fold in HepG2 cells stably expressing CAV1 compared to HepG2 wild-type or GFP-transduced cells. To further explore the potential mechanism a scaffolding domain-defective CAV1 mutant (CAVM1) and a cholesterol shuttle domaindefective CAV1 mutant (CAVM2) were used to investigate the mechanisms of RES transport. CAVM1 transfected into HepG2 cells significantly elevated intracellular concentrations of RES up to 2 fold according to HPLC estimates; this was also consistent with CAV1 transfection experiments.
However, CAVM2, with a non-functioning cholesterol shuttle domain did not enhance RES concentration in cells. More detailed characterization of CAV1-dependet RES transport required the synthesis of RES-dansyl chloride derivatives which could be utilized as fluorescent probes: RES was found to co-localize with CAV1 in HepG2 cells. In addition, RES endocytosis was not mediated through ER $\alpha$ and ER $\beta$, as confirmed by lack of competitive inhibition by estrogens and tamoxifen.

Previous reports indicate that increasing levels of drug resistance are most likely due to decreased topoisomerase 
A
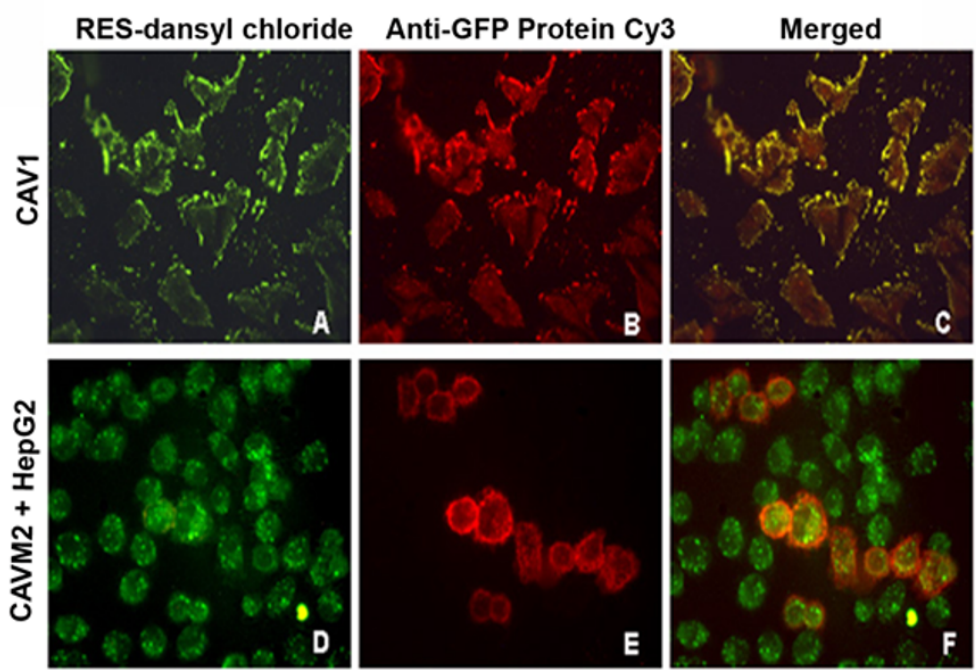

C

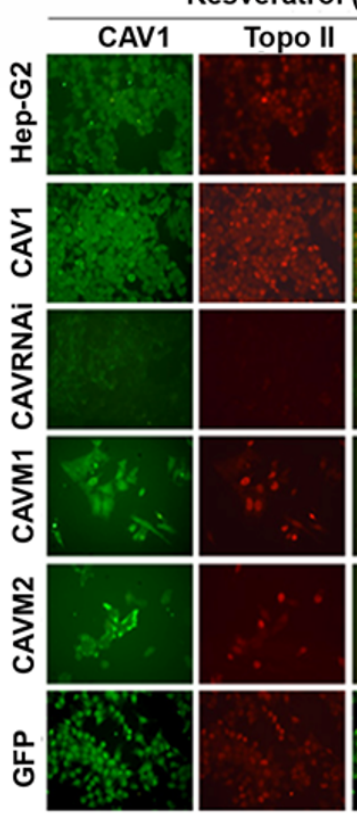

Resveratrol $(100 \mu \mathrm{M})$
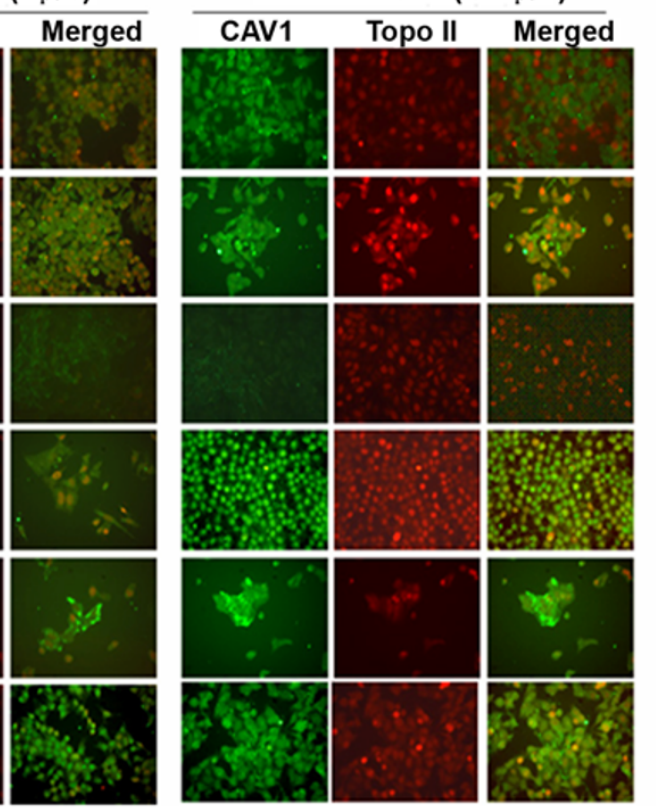

B
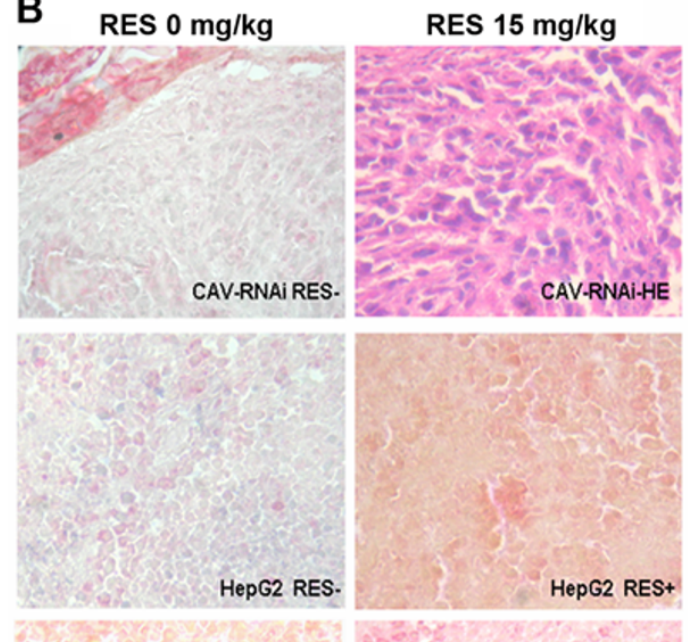

CAV1 RES.
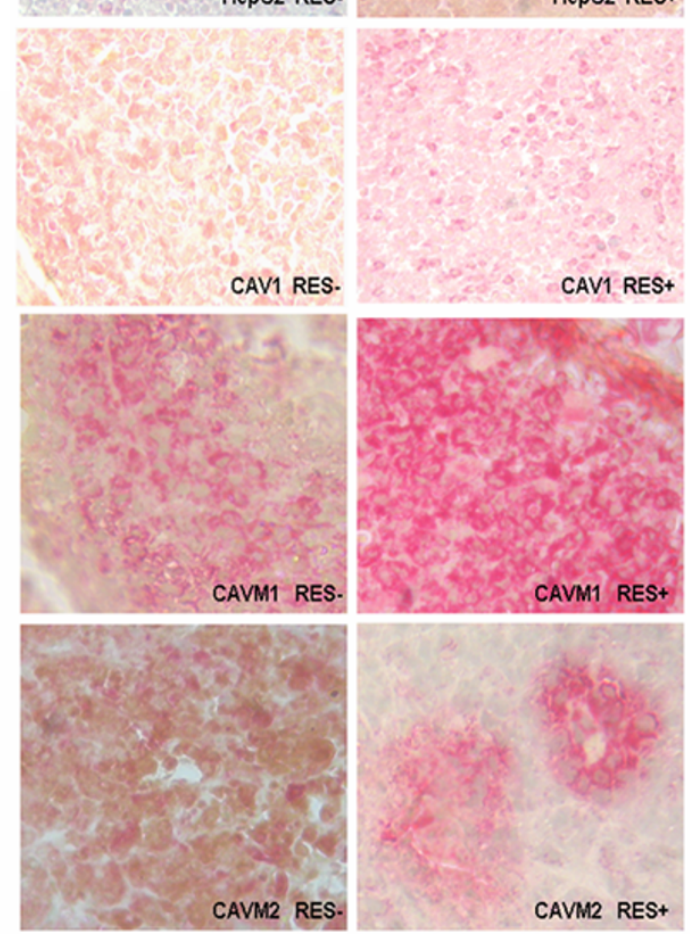

Figure 4

(A) - Co-localization of RES and CAVI in HepG2 cells - Transport of dansyl chloride-derived RES with green fluorescence $(A)$ and recombinant CAVI distribution with red fluorescence (B) and the two combination of both (C). Pooled HepG2 cells and CAVM2 cells bearing green (D) or red fluorescence (E). Over-expression of CAVI by CAVM2 cell groups separates transfected from nontransfected HepG2 cells $(E)$; the images are over-imposed in (F). Experiments were repeated 3 times, with similar results. (B) - Immunohistochemistry of tissue microarrays. (Magnification 400x). Immunoreactivity of CAVI (red) and topoisomerase-alpha (Buffy) in HepG2 variant xenografts with (RES+) or without RES treatment (RES-). (C) Immunofluorescence of CAVI and topoisomerase-alpha - Comparison of untreated (left) or RES-treated for $24 \mathrm{~h}(100 \mu \mathrm{M})$ (right). Localization of CAVI and topoisomerase-alpha was visualized by indirect immunofluorescence. Microphotographs of a single field stained with anti-CAVI (green) and topoisomerase-alpha (red) antibodies. (Magnification 400x) Experiments were repeated 3 times, with similar results.

II protein levels [34]. In this study, we found that RES pretreatment $(100 \mu \mathrm{M})$ promotes the expression of CAV1 or topoisomerase-alpha while topoisomerase-alpha expression is inhibited completely in CAVRNAi cells. However, $100 \mu \mathrm{M}$ RES pre-treatment recovered partially topoi- somerase-alpha expression in CAVRNAi cells. These results displayed that reduced CAV1 protein levels might confer resistance and CAV1 may represent a new tool to avoid multi-drug resistance by cancer cells. Finally, we analyzed the relationship between RES and CAV1 expres- 
A
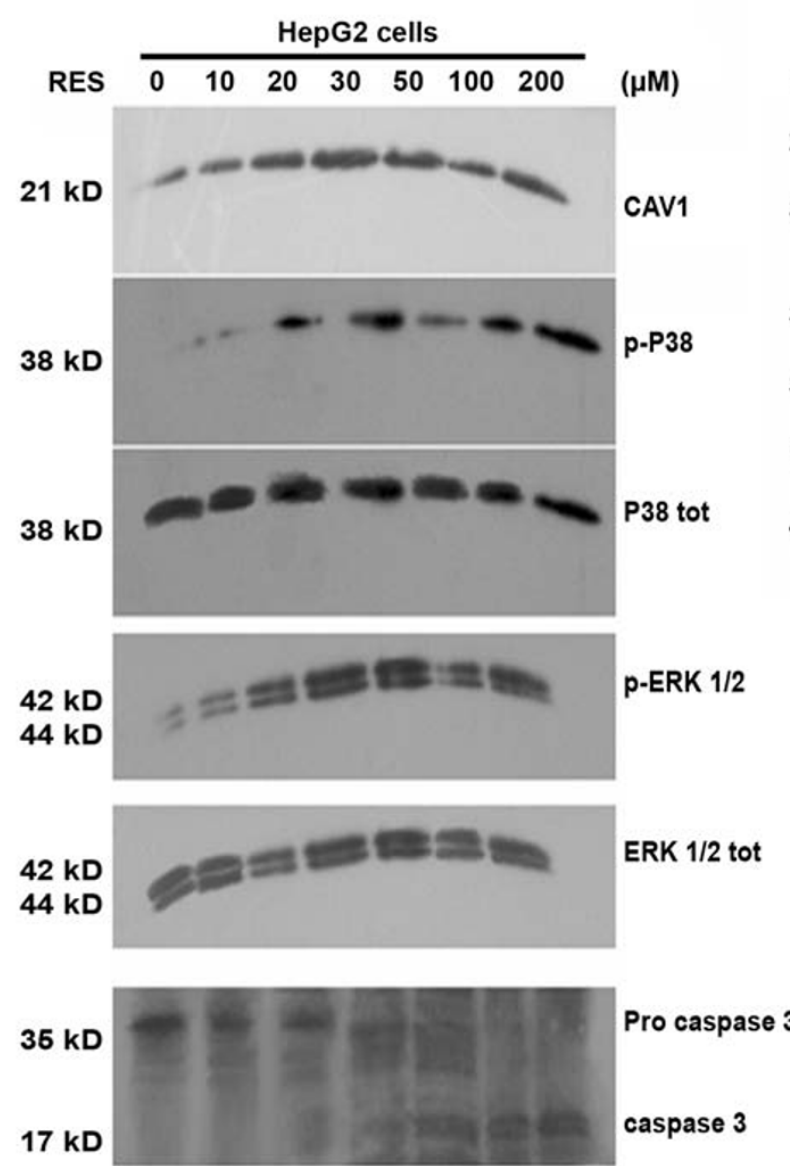

$42 \mathrm{kD}$

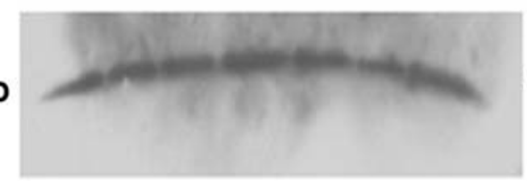

$\beta$-actin
B

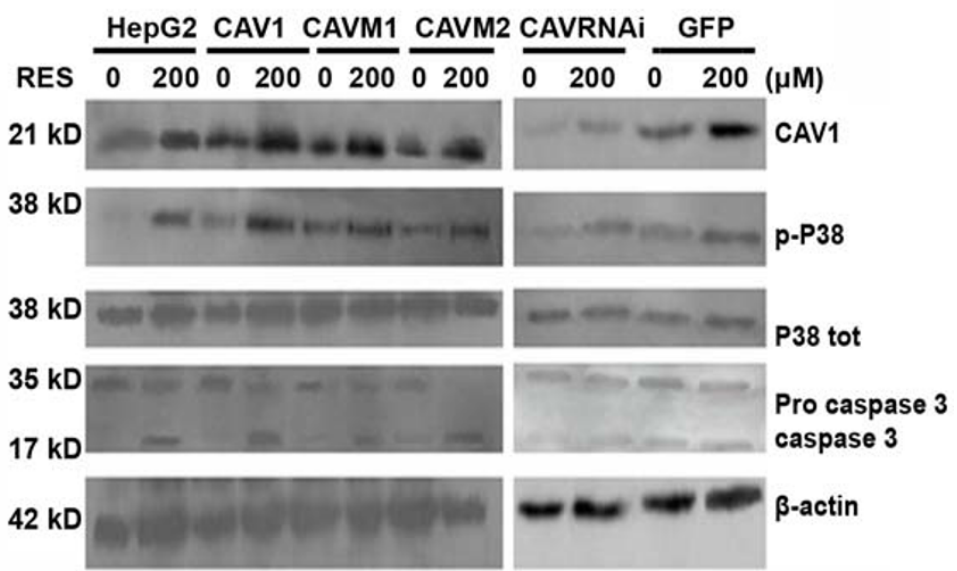

C
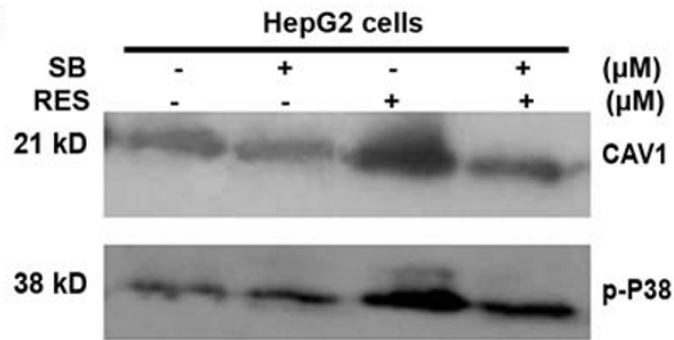

$38 \mathrm{kD}$

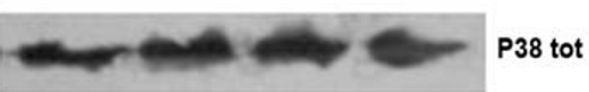

$35 \mathrm{kD}$

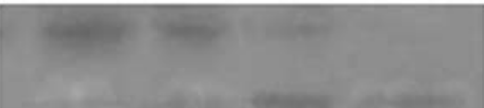

Pro caspase 3

$17 \mathrm{kD}$

caspase 3

$42 \mathrm{kD}$

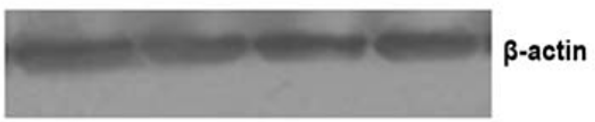

\section{Figure 5}

(A) HepG2 cells were treated for $24 \mathrm{~h}$ with 0-200 $\mu$ M RES; CAVI, MAPKs, and caspase-3 protein levels were further determined by Western blot. (B) - HepG2 variants were treated with $200 \mu M$ RES for 24 h; CAV-I, caspase-3 and MAPKs protein levels were determined by Western blot. (C) - HepG2 variants were pre-treated for 30 minutes with or without $20 \mu \mathrm{M}$ of the P38 inhibitor SB203580 prior to the $24 \mathrm{~h}$ treatment with $200 \mu \mathrm{M}$ RES; CAVI, caspase-3 and MAPKs protein levels were determined by Western blot. Experiments were repeated 3 times, with similar results.

sion and their role in inhibiting proliferation or inducing apoptosis of HepG2 cells. Immunoblotting analysis suggests that RES could up-regulate endogenous CAV1 expression, which further mediates the activation of the inhibitory $\mathrm{p} 38 \mathrm{MAPK}$ cascade pathway and promotes the activation of the pre-apoptotic protein caspase-3.

Overall, this study confirms for the first time that overexpression of CAV1 enhances the transport of RES into HepG2 through its cholesterol shuttle domain rather than the scaffolding domain. This leads, in turn, in inhibition of proliferation and induction of HepG2 cell apoptosis mediated through the p38MAPK pathway and caspase- 3 protein expression.

\section{Competing interests}

The authors declare that they have no competing interests.

\section{Authors' contributions}

HLY set up the protocols, HLY, WQC, XC, DLF, XL and YYX contributed to the experimental procedures and in the interpretation of the data, WYF, EW and FMM gave 
advises on the work and helped with the interpretation of the data, WYF, AW, EW and DFS supervised all the work and wrote the paper together with HLY and MFM. All authors read and approved the final manuscript.

\section{Acknowledgements}

This work was supported by grants from the National Natural Science Foundation of China (No. 30400265 and 3067 I047), Ministry of Education Science and Technology Key Project (No. 207078), the Youth Foundation of Hunan Province Education Department (No. 06B079) and Hunan Provincial Natural Science Foundation of China (08)J3016).

\section{References}

I. Jang M, Cai L, Udeani GO, Slowing KV, Thomas CF, Beecher CW, et al.: Cancer chemopreventive activity of resveratrol, a natural product derived from grapes. Science 1997, 275:218-220.

2. Burkitt MJ, Duncan J: Effects of trans-resveratrol on copperdependent hydroxyl-radical formation and DNA damage: evidence for hydroxyl-radical scavenging and a novel, glutathione-sparing mechanism of action. Arch Biochem Biophys 2000, 38I:253-263.

3. de la Lastra CA, Villegas I: Resveratrol as an anti-inflammatory and anti-aging agent: mechanisms and clinical implications. Mol Nutr Food Res 2005, 49:405-430.

4. Palamara AT, Nencioni L, Aquilano K, De CG, Hernandez L, Cozzolino $F$, et al:: Inhibition of influenza A virus replication by resveratrol. J Infect Dis 2005, 191:1719-1729.

5. Das DK, Maulik N: Resveratrol in cardioprotection: a therapeutic promise of alternative medicine. Mol Interv 2006, 6:36-47.

6. Das S, Das DK: Resveratrol: a therapeutic promise for cardiovascular diseases. Recent Patents Cardiovasc Drug Discov 2007, 2:133-138.

7. Ito T, Akao Y, Yi H, Ohguchi K, Matsumoto K, Tanaka T, et al.: Antitumor effect of resveratrol oligomers against human cancer cell lines and the molecular mechanism of apoptosis induced by vaticanol C. Carcinogenesis 2003, 24: I489-| 497.

8. Fulda S, Debatin KM: Sensitization for tumor necrosis factorrelated apoptosis-inducing ligand-induced apoptosis by the chemopreventive agent resveratrol. Cancer Res 2004, 64:337-346.

9. Zhang Q, Tang X, Lu QY, Zhang ZF, Brown J, Le AD: Resveratrol inhibits hypoxia-induced accumulation of hypoxia-inducible factor-Ialpha and VEGF expression in human tongue squamous cell carcinoma and hepatoma cells. Mol Cancer Ther 2005, 4: 1465-1474.

10. Chan WK, Delucchi $A B$ : Resveratrol, a red wine constituent, is a mechanism-based inactivator of cytochrome P450 $3 A 4$. Life Sci 2000, 67:3103-31I2.

II. Tseng SH, Lin SM, Chen JC, Su YH, Huang HY, Chen CK, et al.: Resveratrol suppresses the angiogenesis and tumor growth of gliomas in rats. Clin Cancer Res 2004, 10:2190-2202.

12. Pozo-Guisado E, Merino JM, Mulero-Navarro S, Lorenzo-Benayas MJ, Centeno F, varez-Barrientos A, et al.: Resveratrol-induced apoptosis in MCF-7 human breast cancer cells involves a caspaseindependent mechanism with downregulation of $\mathrm{Bcl}-2$ and NF-kappaB. Int ] Cancer 2005, I I 5:74-84.

13. Szewczuk LM, Lee SH, Blair IA, Penning TM: Viniferin formation by COX-I: evidence for radical intermediates during co-oxidation of resveratrol. I Nat Prod 2005, 68:36-42.

14. Tyagi A, Singh RP, Agarwal C, Siriwardana S, Sclafani RA, Agarwal R: Resveratrol causes Cdc2-tyrI5 phosphorylation via ATM/ ATR-Chkl/2-Cdc25C pathway as a central mechanism for $S$ phase arrest in human ovarian carcinoma Ovcar-3 cells. Carcinogenesis 2005, 26:1978-1987.

15. Bhat KP, Lantvit D, Christov K, Mehta RG, Moon RC, Pezzuto JM: Estrogenic and antiestrogenic properties of resveratrol in mammary tumor models. Cancer Res 200I, 61:7456-7463.

16. Klinge CM, Blankenship KA, Risinger KE, Bhatnagar S, Noisin EL, Sumanasekera WK, et al: Resveratrol and estradiol rapidly activate MAPK signaling through estrogen receptors alpha and beta in endothelial cells. J Biol Chem 2005, 280:7460-7468.
17. Galluzzo P, Caiazza F, Moreno S, Marino M: Role of ERbeta palmitoylation in the inhibition of human colon cancer cell proliferation. Endocr Relat Cancer 2007, 14:153-167.

18. Rejman J, Conese M, Hoekstra D: Gene transfer by means of lipo- and polyplexes: role of clathrin and caveolae-mediated endocytosis. J Liposome Res 2006, 16:237-247.

19. Razani B, Schlegel A, Liu J, Lisanti MP: Caveolin-I, a putative tumour suppressor gene. Biochem Soc Trans 200I, 29:494-499.

20. Ho CC, Huang PH, Huang HY, Chen YH, Yang PC, Hsu SM: Up-regulated caveolin-I accentuates the metastasis capability of lung adenocarcinoma by inducing filopodia formation. Am J Pathol 2002, 16I:1647-1656.

21. Liu P, Rudick M, Anderson RG: Multiple functions of caveolin-I. J Biol Chem 2002, 277:4 | 295-4I 298.

22. Peterson TE, Guicciardi ME, Gulati R, Kleppe LS, Mueske CS, Mookadam M, et al: Caveolin-I can regulate vascular smooth muscle cell fate by switching platelet-derived growth factor signaling from a proliferative to an apoptotic pathway. Arterioscler Thromb Vasc Biol 2003, 23:152I-I527.

23. Duxbury MS, Ito $\mathrm{H}$, Ashley SW, Whang EE: CEACAM6 cross-linking induces caveolin-I-dependent, Src-mediated focal adhesion kinase phosphorylation in BxPC3 pancreatic adenocarcinoma cells. J Biol Chem 2004, 279:23 I 76-23 I82.

24. Graziani A, Bricko V, Carmignani M, Graier WF, Groschner K: Cholesterol- and caveolin-rich membrane domains are essential for phospholipase A2-dependent EDHF formation. Cardiovasc Res 2004, 64:234-242.

25. Bowers JL, Tyulmenkov VV, Jernigan SC, Klinge CM: Resveratrol acts as a mixed agonist/antagonist for estrogen receptors alpha and beta. Endocrinology 2000, I41:3657-3667.

26. Yang H, He S, Quan Z, Peng W, Yan B, Liu J, et al.: Small interfering RNA-mediated caveolin-I knockout on plasminogen activator inhibitor-I expression in insulin-stimulated human vascular endothelial cells. Acta Biochim Biophys Sin (Shanghai) 2007, 39:224-233

27. Xu YY, Yang HL, Tu J: The construction, Identification and primary functional analysis of pcDNA3.I/NT-GFP-Caveolin-I and mutants plasmids. Chin J Atheroscler 2006, 13:297-300.

28. Yang HL, Jiang HJ, Fang WY, Xu YY, Liao DF, He FC: High fidelity PCR with an off/on switch mediated by proofreading polymerases combining with phosphorothioate-modified primer. Biochem Biophys Res Commun 2005, 328:265-272.

29. Yang HL, Xu YY, DU LF, Liu CH, Zhao Q, Wei WJ, et al:: Chemokine SR-PSOX/CXCLI6 expression in peripheral blood of patients with acute coronary syndrome. Chin MedJ (Engl) 2008, I 2 I: I I2-II7.

30. Quan Z, Yang H, Yang Y, Yan B, Cao R, Wen G, et al:: Construction and functional analysis of a lentiviral expression vector containing a scavenger receptor (SR-PSOX) that binds uniquely phosphatidylserine and oxidized lipoprotein. Acta Biochim Biophys Sin (Shanghai) 2007, 39:208-216.

31. Yerian LM, Anders RA, Tretiakova M, Hart J: Caveolin and thrombospondin expression during hepatocellular carcinogenesis. Am J Surg Pathol 2004, 28:357-364.

32. Torres VA, Tapia JC, Rodriguez DA, Parraga M, Lisboa P, Montoya M, et al.: Caveolin-I controls cell proliferation and cell death by suppressing expression of the inhibitor of apoptosis protein survivin. J Cell Sci 2006, I I9:1812-1823.

33. Pakunlu RI, Wang Y, Tsao W, Pozharov V, Cook TJ, Minko T: Enhancement of the efficacy of chemotherapy for lung cancer by simultaneous suppression of multidrug resistance and antiapoptotic cellular defense: novel multicomponent delivery system. Cancer Res 2004, 64:6214-6224.

34. Hazlehurst LA, Argilagos RF, Emmons M, Boulware D, Beam CA, Sullivan DM, et al.: Cell adhesion to fibronectin (CAM-DR) influences acquired mitoxantrone resistance in $\mathbf{U 9 3 7}$ cells. Cancer Res 2006, 66:2338-2345. 